\title{
The challenge to verify ceramide's role of apoptosis induction in human cardiomyocytes - a pilot study
}

\author{
Engin Usta ${ }^{1 *}$, Migdat Mustafi ${ }^{2}$, Ferruh Artunc $^{3}$, Tobias Walker ${ }^{2}$, Vladimir Voth ${ }^{2}$, Hermann Aebert ${ }^{4}$ and \\ Gerhard Ziemer ${ }^{1}$
}

\begin{abstract}
Background: Cardioplegia and reperfusion of the myocardium may be associated with cardiomyocyte apoptosis and subsequent myocardial injury. In order to establish a pharmacological strategy for the prevention of these events, this study aimed to verify the reliability of our human cardiac model and to evaluate the pro-apoptotic properties of the sphingolipid second messenger ceramide and the anti-apoptotic properties of the acid sphingomyelinase inhibitor amitryptiline during simulated cardioplegia and reperfusion ex vivo.

Methods: Cardiac biopsies were retrieved from the right auricle of patients undergoing elective CABG before induction of cardiopulmonary bypass. Biopsies were exposed to ex vivo conditions of varying periods of $\mathrm{cp} / \mathrm{rep}$ (30/10, 60/20, 120/40 min). Groups: I (untreated control, $n=10)$, II (treated control cp/rep, $n=10)$, III (cp/rep + ceramide, $n=10)$, IV (cp/rep + amitryptiline, $n=10)$ and $V(c p / r e p+$ ceramide + amitryptiline, $n=10)$. For detection of apoptosis anti-activated-caspase-3 and PARP-1 cleavage immunostaining were employed.
\end{abstract}

Results: In group I the percentage of apoptotic cardiomyocytes was significantly $(p<0.05)$ low if compared to group II revealing a time-dependent increase. In group III ceramid increased and in group IV amitryptiline inhibited apoptosis significantly $(p<0.05)$. In contrast in group $V$, under the influence of ceramide and amitryptiline the induction of apoptosis was partially suppressed.

Conclusion: Ceramid induces and amitryptiline suppresses apoptosis significantly in our ex vivo setting. This finding warrants further studies aiming to evaluate potential beneficial effects of selective inhibition of apoptosis inducing mediators on the suppression of ischemia/reperfusion injury in clinical settings.

\section{Introduction}

Cardioplegia and reperfusion of the myocardium are essential techniques employed in many cardiac surgical procedures when a temporarily arrested myocardium is required. However, as a consequence of exposure to cardioplegia and reperfusion apoptosis of cardiomyocytes may occur [1]. Apoptosis is the ultimate result of multiple convergent signalling pathways, which are triggered by events such as nutrient and oxygen deprivation, intracellular calcium overload and excessive reactive oxygen species production [1]. In the setting of cardiac

\footnotetext{
* Correspondence: engin.usta@gmx.de

'Children's University Hospital, Div. Congenital \& Pediatric Cardiac Surgery;

University Hospital Tübingen, Germany

Full list of author information is available at the end of the article
}

surgery these events can finally result in contractile dysfunction of the myocardium [2] and atrial fibrillation [3]. Apoptosis of cardiac non-myocytes also contributes to maladaptive remodelling and the transition to decompensated congestive heart failure [4]. Regarding this potentially impact of apoptosis on clinical outcomes, there is a demand for pharmacological strategies. Pharmacological blockade has been shown to reduce apoptosis during extracorporeal circulation in an animal model [5]. In contrast to that we have successfully established a human cardiac model, which we have presented recently [6-8].

Our present pilot study was performed just as a sequel to our recent work [6-8] to further evaluate our presented human cardiac model during simulated cardioplegia and

\section{C) Biomed Central}


reperfusion ex vivo respectively the end-points feasibility and reliability. We conducted this study to clarify if another pathway of apoptosis induction in cardiomyocytes exists. Our aim was to evaluate during ex vivo simulated cardioplegia and reperfusion the effect of the sphingolipid second messenger ceramide and the anti-apoptotic properties of the sphingomyelinase inhibitor amitryptiline respectively the end-point apoptosis induction and reduction in cardiomyocytes which to our knowledge has not been described in such an experimental setting yet. The results should clarify if any clinical potential utilization could be favoured.

\section{Materials and methods}

\section{Ethics declaration}

The investigation conforms with the principles outlined in the Declaration of Helsinki. In addition, approval was granted by the Ethics Committee of the Faculty of Medicine of the Eberhard-Karls-University, Tübingen, Germany (approval reference number 40/2007 V).

\section{Patient characteristics}

The study protocol was approved by the ethics committee of the Faculty of Medicine of the EberhardKarls-University Tübingen. 20 patients undergoing elective CABG surgery were included in this study and gave informed consent for study participation. Mean patient age was 65 years (range 45-70). Mean body mass index $28 \mathrm{~kg} / \mathrm{m}^{2}$ (range 25-32). Mean left ventricular ejection fraction 63\% (range 55-75). Mean number of diseased coronary vessels 3 (range 2-3). Mean number of infarctions 1 (range 1-3) in patients history. The basic medication of all patients consisted of $\beta$-blockers (Beloc Zok $^{\mathrm{TM}} 47.5 \mathrm{mg}$ twice per die, angiotensin converting enzyme inhibitors, statins and diuretics. All patients had a sinus rhythm.

\section{Material}

Human tissue was retrieved from the auricle of the right atrium of patients before cardiopulmonary-bypass (CPB) and was processed immediately. Each biopsy was transmuraly divided in thirteen pieces with [0.5 to $1 \mathrm{~cm}^{2}$ ] size, which were placed separately in microperfusion chambers with continuous perfusion. Cardiac specimens were outside the body before being mounted and tested in the chamber system for a maximum of $30 \mathrm{~min}$, but during this period the oxygen supply was maintained continuously by bubble-oxygenating the Krebs-Henseleit buffer in the petri dish (Greiner Bio-One, Frickenhausen Germany).

\section{Chemicals and buffer solutions}

The modified Krebs-Henseleit buffer $(\mathrm{KH})$ consisted of $115 \mathrm{mM} \mathrm{NaCl}, 4.5 \mathrm{mM} \mathrm{KCl}, 1.18 \mathrm{mM} \mathrm{MgCl}_{2}, 1.25 \mathrm{mM}$
$\mathrm{CaCl} 2,1.23 \mathrm{mM} \mathrm{NaH} \mathrm{PO}_{4}, 1.19 \mathrm{Na}_{2} \mathrm{SO}_{4}, 80 \mathrm{mM}$ Glucose, and $10 \mathrm{mM}$ HEPES, pH adjusted to 7.4 at $37^{\circ} \mathrm{C}$ with $\mathrm{NaOH}$.

\section{Cardioplegic solution}

Cardioplegic solution was prepared on the basis of $\mathrm{Ca}$ free $\mathrm{KH}$ consisting of $115 \mathrm{mM} \mathrm{NaCl}, 4.5 \mathrm{mM} \mathrm{KCl}$, $1.18 \mathrm{mM} \mathrm{MgCl}_{2}, 0.5 \mathrm{mM}$ EGTA, $1.23 \mathrm{mM} \mathrm{NaH}_{2} \mathrm{PO}_{4}$, $1.19 \mathrm{mM} \mathrm{Na}_{2} \mathrm{SO}_{4}, 80 \mathrm{mM}$ Glucose, and $10 \mathrm{mM}$ HEPES, $\mathrm{pH}$ adjusted to 7.4 at $37^{\circ} \mathrm{C}$ with $\mathrm{NaOH}$. Furthermore, a solution containing $20 \mathrm{mM}$ Tris hydroxymethyl-aminomethane, $60 \mathrm{mmol} \mathrm{K} \mathrm{K}^{+}$and anionic polypeptides to the isoionic point was added in a 1:4 proportion to $\mathrm{Ca}$-free $\mathrm{KH}$ buffer. This solution served as cardioplegic solution and was administered at $4^{\circ} \mathrm{C}$, in analogy to our clinical regimen. The resulting $\mathrm{K}^{+}$concentration in this mixture was $16.5 \mathrm{mM}$.

\section{Ceramide}

Sphingolipids are constituents of cellular membranes and of lipoproteins. The common backbone is the long chain amino base sphingosine (trans-4-sphingenine), and the ceramides refer to the $N$-acyl derivatives of sphingosine. For a decade now, ceramides have been widely studied as regulators of major cellular functions, i.e., apoptosis, proliferation, or senescence [9-11]. Apoptosis induction with short chain ceramide $(20-50 \mu \mathrm{M})$ supports the view that ceramides are able to trigger apoptosis [12]. The concentration of ceramide employed in this study was $50 \mu \mathrm{M}$, similar to previous experimental settings [12].

\section{Amitryptiline}

Amitryptiline (systematic taxonomy: 3-(10,11-dihydro$5 \mathrm{H}$-dibenzo[[a, d] $]$ cycloheptene-5-ylidene)-N, Ndimethyl-1-propanamine) is a tricyclic antidepressant. Besides its known clinical use it has been identified as an acid sphingomyelinase inhibitor with lowering ceramide levels and thus carrying out anti-apoptotic properties $[13,14]$.

\section{Cell viability}

The viability of cardiomyocytes in tissue samples was assessed by trypan blue exclusion before each experiment. Only samples consisting of $\geq 99 \%$ viable cardiomyocytes were further processed in the experiments of this study.

\section{Microperfusion chamber}

Our self developed, previously described [6-8] microperfusion chamber was modified to investigate larger specimens. It consisted of two components (Figure 1). The first component a temperature-controlled plexiglas block contained a rectangular cavity forming the 


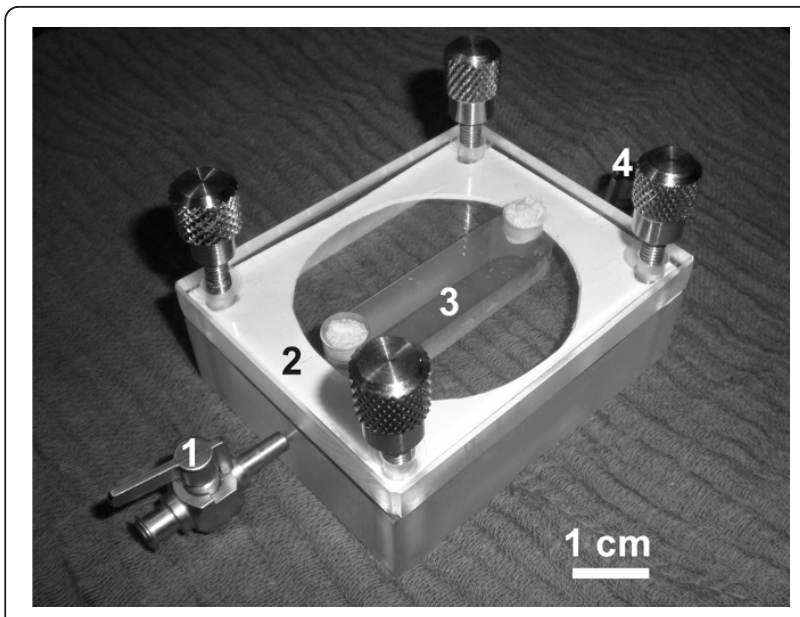

Figure 1 Microperfusion chamber. The perfusate enters the chamber, constructed from plexiglas (2), through the pipe (1) and fills the rectangular shaped chamber (3). Once laminar flow is constituted the cardiac tissue is physically fixed before the nylon net (not featured), which spans in a $135^{\circ}$ angle. The fluid exits on the opposite side (4). Between the bottom and the upper part of the chamber a rubber layer was placed for sealing and fastened with 4 screws.

chamber with following dimensions (length $x$ width $x$ height, $5.5 \times 1.5 \times 1.25 \mathrm{~cm}$ ). The second component was mounted over the first, and consisted of another plexiglas block forming the ceiling of the chamber. In this chamber nylon net with a pore size of $400 \mu \mathrm{m}$ was mounted diagonally. To enable perfusion of the chamber, a thin pipe was introduced at one end of the plexiglas component, entered the chamber and exited at the other end. A thin rubber layer between each component sealed the microperfusion chamber. The biopsy was fixed physically at the nylon net by the laminar flow (perfusion velocity of $5 \mathrm{ml} / \mathrm{min}$ ) of the hydrostatic perfusion system through the chamber.

\section{Experimental groups}

The protocol was designed to simulate clinical routine procedures administering cardioplegic solution with the same $\mathrm{K}^{+}$concentration $(16.5 \mathrm{mM})$ and temperature $\left(4^{\circ} \mathrm{C}\right)$. Five different groups $(\mathrm{I}-\mathrm{V})$ were arranged as follows: I (untreated control, $\mathrm{n}=10$ ), II (treated control $\mathrm{cp} / \mathrm{rep}, \mathrm{n}=10)$, III (cp/rep + ceramide, $\mathrm{n}=10)$, IV $(\mathrm{cp} /$ rep + amitryptiline, $\mathrm{n}=10)$ and $\mathrm{V}(\mathrm{cp} / \mathrm{rep}+$ ceramide + amitryptiline, $\mathrm{n}=10$ ). In group III cardiomyocytes were continuously treated with $50 \mu \mathrm{M}$ ceramid. In In group IV cardiomyocytes were continuously treated with $100 \mu \mathrm{M}$ amitryptiline. In contrast to that in group $\mathrm{V}$ cardiomyocytes were continuously treated with both drugs ceramid $[50 \mu \mathrm{M}]$ and amitryptiline $[100 \mu \mathrm{M}]$. In general, each assay was carried out with the specimens of one patient, i.e. specimens of patients were analysed separately.

\section{Ischemia/reperfusion assay}

The cardiac specimens in the microperfusion chambers were initially equilibrated with $\mathrm{KH}$ for $5 \mathrm{~min}\left(32^{\circ} \mathrm{C}\right.$ and continuously bubble-oxygenated with carbogen $\left(95 \% \mathrm{O}_{2}\right.$ and $5 \% \mathrm{CO}_{2}$ ) to attain a $\mathrm{PO}_{2}$ of $25-30 \mathrm{kPa}$ and $\mathrm{pH} 7.4$. After that the cardioplegic solution $\left(4^{\circ} \mathrm{C}\right)$ was administered for $5 \mathrm{~min}$. To induce ischemic injury during the cardioplegia period the perfusion of the microperfusion chamber was stopped and the oxygen supply was discontinued. The cardiac specimens were subjected to various periods of cardioplegia (30,60 or $120 \mathrm{~min}$ ) followed by $1 / 3$ of the chosen cardioplegia time as reperfusion $(10,20$ or $40 \mathrm{~min})$, as in our surgical routine. For reperfusion $35^{\circ} \mathrm{C} \mathrm{KH}$ was used. Finally, the cardiac specimens were snap-frozen in liquid nitrogen.

\section{Immunohistochemical apoptosis detection}

The slides with the cryosections of the samples $(10 \mu \mathrm{m})$ were processed prior to the staining according to the manufacturer's recommendation (Epitomics, Inc., Burlingame, CA, USA). The described chemicals were purchased from Biochrom, Berlin Germany. In brief, the cryosections were immersed into the staining dish containing the antigen retrieval solution: $9 \mathrm{ml}$ of stock solution A (0.1 M citric acid solution) and $41 \mathrm{ml}$ of stock solution B ( $0.1 \mathrm{M}$ sodium citrate solution) were added to $450 \mathrm{ml}$ of destillated $\mathrm{H}_{2} \mathrm{O}$ and adjusted to $\mathrm{pH} 6.0$. After warming for $30 \mathrm{~min}$ in a rice cooker and cooling down the slides were washed with TBST (Tris-Buffered Saline and $0.1 \%$ Tween 20) for $5 \mathrm{~min}$ on a shaker. For the inactivation of endogenous peroxidases the slides were covered with $3 \%$ hydrogen peroxide for $10 \mathrm{~min}$ and later washed with TBST. After that the slides were immersed into the blocking solution (PBS (Dulbecco's Phosphate Buffered Salts) and 10\% bovine serum albumin) for 1 hour.

Later the cryosections were incubated overnight in a humidified chamber $\left(4^{\circ} \mathrm{C}\right)$ with antibodies against PARP-1 (Anti-Poly-(ADP-Ribose)-Polymerase)-cleavage (Epitomics, Inc.). PARP is a zinc-dependent DNA binding protein that recognizes DNA strand breaks and is presumed to play a role in DNA repair. PARP is cleaved in vivo by caspase-3 [15]. The antibody only recognizes p25 cleaved-form of PARP-1.

On the other hand cryosections were stained with antibodies against activated Caspase-3 (Epitomics, Inc.), also. Caspases are a family of cytosolic aspartate-specific cysteine proteases involved in the initiation and execution of apoptosis. Caspase-3 (apopain, SCA-1, Yama and CPP32) is a member of the apoptosis execution functional group of caspases, and is either partially or totally responsible for the proteolytic cleavage of many key proteins during apoptosis. Caspase- 3 is a cytosolic protein found in cells as an inactive $35 \mathrm{kDa}$ proenzyme. It is 
activated by proteolytic cleavage into two active subunits only when cells undergo apoptosis (3).

Later for detection to each section secondary HRPconjugated anti-rabbit antibody (Epitomics, Inc.) diluted in the blocking solution per manufacturer's recommendation was applied and incubated for 1 hour at room temperature.

\section{Fluorescence microscopy}

The number of cells on the cryosections was determined by counting the nuclei of cardiomyocytes after staining with DAPI (4',6-Diamidino-2-phenylindole $2 \mathrm{HCl}$ ), a dye known to form fluorescent complexes with natural double-stranded DNA, under a fluorescence microscope (Zeiss, Jena, Germany). In each analysis three different areas of the cryosections were counted using 40-fold magnification. Apoptotic cells were identified by condensation and fragmentation of the nuclei and fluorescent conglomerates in the cytoplasm. They were quantified by counting a total of 200 nuclei from each cryosection and calculating the percentage of apoptotic nuclei. After DAPI counterstaining the greater nuclei of cardiomyocytes allow their distinction from fibroblasts with smaller nuclei. In anti-activated caspase-3 positive, apoptotic cardiomyocytes the cytoplasm reveales an intensive granular fluorescence (Figure 2). In contrast to that PARP-1 cleavage positive, apoptotic cardiomyocytes nuclei feature an intensive granular fluorescence intensity with granular staining of the nucleus.

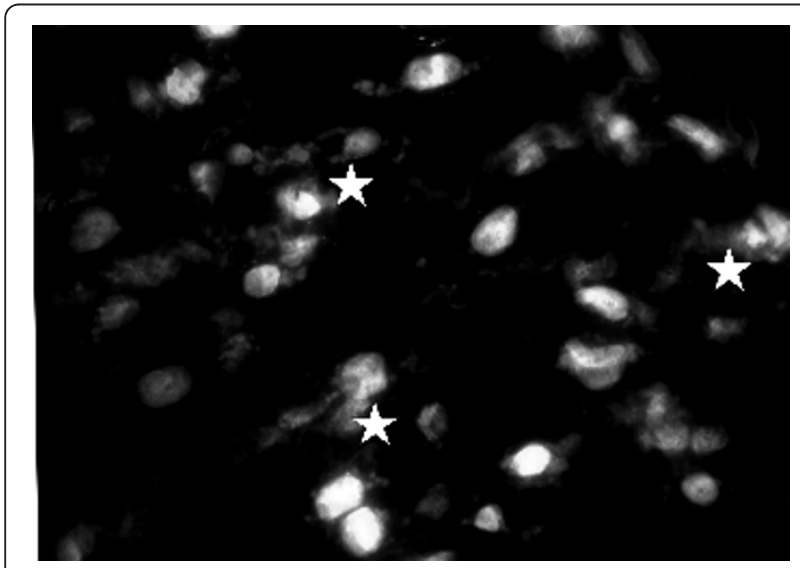

Figure 2 Representative fluorescent image of cardiomyocytes treated with ceramide during cardioplegia (60 $\mathrm{min}$ ) and reperfusion (20 $\mathrm{min}$ ) (group III). After DAPI counterstaining the greater nuclei of cardiomyocytes allow their distinction from fibroblasts with smaller nuclei. In anti-activated caspase-3 positive, apoptotic cardiomyocytes the cytoplasm reveales an intensive granular fluorescence (marked with stars). The exemplary images represent a single experiment. During the cryosection procedure artifacts presenting as nuclei conglomerates could not be avoided; these were excluded from analyses.
Fluorescence images (blue) of DAPI loaded cardiac specimens were obtained at an excitation wavelength of $360 \mathrm{~nm}$, with an emission wavelength of $460 \mathrm{~nm}$. DAPI was purchased from Sigma-Aldrich, Germany.

\section{Statistical Analysis}

Analysis of calcium recordings and graphics were obtained using Sigma Plot software (version 9.0, SPSS Inc., Chicago, IL). Data are expressed as the mean \pm standard error of deviation (SD) and statistical analysis was performed using GraphPad Prism (version 5.0, GraphPad Software, Inc., CA, USA). Comparison of groups was performed using repeated measures one-way ANOVA followed by Tukey's HSD post hoc test. A p value of less than 0.05 was considered to indicate a statistically significant difference.

\section{Results}

Immunohistochemical apoptosis detection

Anti-activated-caspase-3

Cardiomyocytes in the untreated group I revealed a significant $(\mathrm{p}<0.05)$ low percentage of apoptotic cells $(12 \pm 5 \%)$ in comparison to the treated control group II (Figure 3A). There was a significant $(\mathrm{p}<0.05)$ lower percentage of apoptotic cells in the amitryptiline treatment group IV if compared to group III with ceramide (Figure 3A).

\section{PARP-1 cleavage}

Cardiomyocytes in the untreated group I featured a significant $(\mathrm{p}<0.05)$ low percentage of apoptotic cells $(12 \pm 4 \%)$ in comparison to the treated control group II (Figure 3B). There was a significant $(\mathrm{p}<0.05)$ lower percentage of apoptotic cells in the amitryptiline treatment group IV if compared to group III with ceramide (Figure 3B).

\section{Discussion}

In the present study our first goal was to apply ceramide to evaluate the proapoptotic potential during cardioplegia and reperfusion $[9,16]$ in an ex vivo setting with human cardiomyocytes which to our current knowledge has not been reported yet. Our second goal was to investigate if the proapoptotic effect of ceramide could be inhibited by amitryptiline [17]. Our third goal was just in accordance to our clinical routine to administer cardioplegia and reperfusion to simulate the extracorporeal circulation in our experimental model and evaluate if the induction or inhibition of apoptosis could be influenced.

In our experimental model human cardiomyocytes were kept in their natural environment as intact cardiac tissue. Otherwise human papillary muscle could be employed but obtaining it before cardioplegic arrest is not an imaginable and feasible option during 


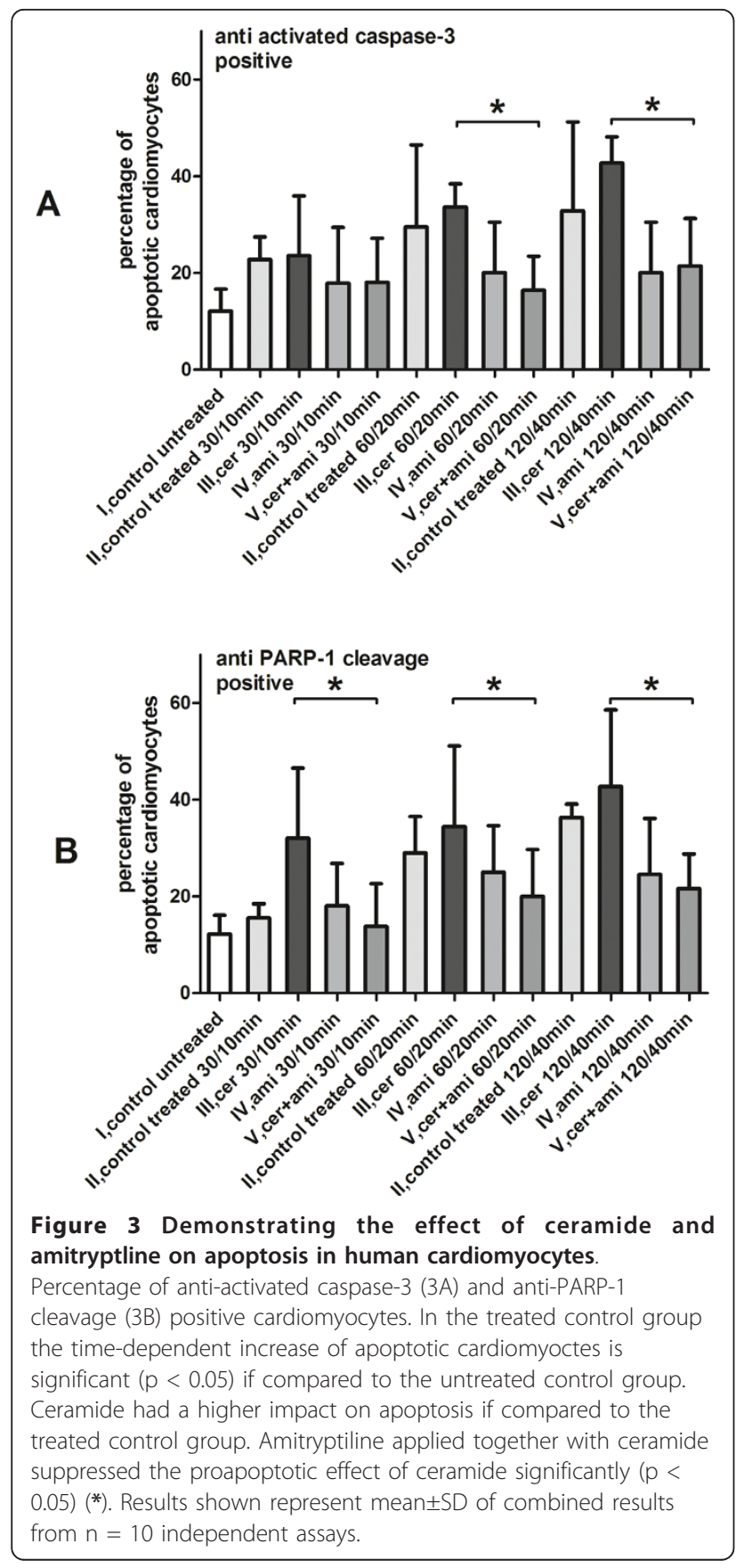

clinical routine. The simulation of ischemia in isolated cardiomyocyte models can provide important insights into the pathophysiology of myocardial ischemic injury and its underlying molecular mechanisms as was the subject in previous studies in isolated mammalian cardiomyocytes [18], isolated papillary muscle preparations [19] or animal heart models [20]. The distinctive difference of our experimental assay was utilizing human atrial cardiac tissue as a model for apoptosis studies inducing apoptotis just in accordance to our clinical routine with cardioplegia and reperfusion without induction of ischemia with $\mathrm{N}_{2}$ perfusion like in previous studies [21,22]. Like presented above in our experimental assay the cardioplegia and reperfusion stimulus proved to be an adequate stimulus for apoptosis induction and is comparable with those in the literature [6-8,23].

Further we wanted to enlighten the major mediators of apoptosis occurring during postischemic reperfusion. Apoptosis is an important mechanism of active cellular death that is distinct from necrosis and has been implicated in the pathogenesis of a variety of degenerative and ischemic human diseases [24]. The family of caspases is key mediator of apoptosis. An extrinsic pathway involving cell surface death receptors [25] and an intrinsic pathway with intracellular and extracellular death signals which are transmitted to the mitochondria through members of the Bcl-2 family [26] exist. Several intracellular stimuli, including oxidative stress, translocate Bax and/or Bak to the mitochondria, leading to dysfunction of this organelle, the release of proapoptotic proteins, and the activation of caspase-9 [27]. Another important stimulus for apoptosis derive from sphingolipids like ceramides which have been described as second messengers for several events like differentiation, senescence, proliferation and cell death in different cell lines [9]. Sphingolipids are found in most subcellular membranes. In the plasma membrane they are predominantly found in the outer leaflet [28]. The metabolism of sphingolipids has been proved to be a dynamic process and their metabolites (such as ceramide, sphingosine, and sphingosine 1-phosphate (S1P)) are now recognized as messengers playing essential roles in cell growth, survival, as well as cell death $[9,29]$. Sphingomyelin (SM) is a ubiquitous component of animal cell membranes, where it is by far the most abundant sphingolipid. Ceramide can be formed through sphingomyelinases (SMase)-dependent catabolism of SM and by de novo synthesis. SMases are specialized enzymes with phospholipase $\mathrm{C}$ activity that can hydrolyze the phosphodiester bond of SM. It is well known that ceramide can modulate many different cellular processes. Ceramide directly regulates protein phosphatase 1 (PP1), inducing dephosphorylation of SR proteins and splicing of caspase- 9 and $\mathrm{Bcl}-\mathrm{x}$ genes [30]. Interaction of ceramide with protein kinase-c can inhibit translocation of the kinase to the plasma membrane and therefore inhibits its catalytic activity. Finally the intrinsic and extrinsic pathways of apoptosis induction converge and lead to the activation of caspases which have been characterized as major executioners of apoptosis [31]. During oxidative stress reactive oxygen species trigger the release of cytochrome c from mitochondria and, subsequently, caspase activation. Active caspases promote cellular demolition by activating other destructive enzymes, such 
as DNAses, and by directly targeting key structural proteins, such as lamin and actin, and regulatory proteins, thus leading to chromatin margination, DNA fragmentation, nuclear condensation and collapse [31], which we could demonstrate in our immunohistochemical assays.

In our experiments, we found that caspase- 3 was already activated at the end of the ischemia, thus suggesting that the mitochondrial pathway of apoptosis is a very early event in myocardial injury. Caspase- 3 has been shown to cleave the $112 \mathrm{kDa}$ nuclear protein PARP into an $85 \mathrm{kDa}$ apoptotic fragment [32], and this cleavage by caspase- 3 has been shown to be necessary for apoptosis [15]. In this regard, the nuclear presence of proteolytic fragments of PARP has been considered a hallmark of an apoptotic cell. However, the role of PARP-1 in apoptosis remains to be determined because conflicting data have been reported. Some investigators have shown that neurons or hepatocytes from PARPdeficient mice do not exhibit any altered sensitivity to apoptotic stimuli, whereas others have demonstrated that pharmacological or genetic inhibition may increase apoptosis in cells subjected to alkylating agents [33,34]. The family of Bcl-2-related proteins constitutes the most relevant class of apoptotic regulators and, more specifically, the ratio of anti- or pro-apoptotic proteins determines whether the cell will survive or die $[35,36]$. On the other hand, expression of Bcl-2 protein prevents the induction of apoptosis caused by a variety of oxidative stresses, and it can influence the level of caspase activation [35]

In accordance to this referred data in our presented study we could demonstrate that apoptosis can be suppressed effectively in our experimental setup. Considering our immunohistochemical apoptosis detection there is a significant reduction of apoptosis in cardiomyocytes treated with amitryptiline in contrast to the treatment with ceramide after cardioplegia and succeeding reperfusion. The high apoptosis rate in the treated control group especially after $120 \mathrm{~min}$ cardioplegia and $40 \mathrm{~min}$ reperfusion should not be extrapolated into the in vivo situation without any caution as atrial and ventricular myocardium possess specific characteristics that may influence the susceptibility to ischaemia/reperfusion injury. One explanation is the reported difference in the distribution of potassium channels [37], which contributes to the characteristic differences between atrial and ventricular action potentials and may determine a different response to cardioplegia/reperfusion.

Our presented data provide evidence that one of the key signaling pathways controlling apoptosis could mediate, at least in part, ischemia-reperfusion induced injury. Furthermore, the results of our study suggest that, although proapoptotic signalling plays an important role in the development of reperfusion-induced damage, acid sphingomyelinase inhibition by amitryptiline aside from dose-dependency may not afford alone a complete protection against postischemic damage. This characteristic has been described in previous studies [14] and could be an explanation for the partial inhibition of apoptosis due to the treatment with amitryptiline like presented in this study.

\section{Limitations}

The present study has few potential limitations. First, clinical ischemia might be quite different from the simulated ischemia we use. Unfortunately, there is currently no accepted standard that constitutes a clinically relevant "simulated ischemic exposure" for cells. Simulating the ischemic environment of the extracellular fluid that bathes the cells is quite complex due to the fact that there are alterations in many factors, simulating all of these events is not currently possible. So, whereas the use of simulated ischemia is not perfect, we believe it recreates a number of the important components of clinical ischemia. Further in this study only a single ceramid and amitryptiline concentration was employed, but analogous to previous studies in a pharmacological relevant concentration [38]. Therefore, detailed doseresponse relationships of neither ceramide nor amitryptiline on apoptotic events were not investigated. Nevertheless, with the concentration employed in this study, apoptotic events could be triggered or inhibited considerably. Furthermore the primary purpose of this study was to test its effect on apoptotic events in cardiomyocytes in this new experimental setting rather than to study doseresponse relationships. Our next step would be to verify our current findings in an animal model. However our results indicate a definite beneficial effect of amitryptiline on apoptotic events.

\section{Conclusions}

In human cardiomyocytes there is a remarkable induction of apoptosis due to the pro-apoptotic second messenger ceramide.

The treatment of human cardiomyocytes in an ex vivo experimental setting with simulated cardioplegia and reperfusion can result in considerable reduction of apoptotic events by adding amitryptiline. These findings warrant further studies in order to evaluate potentially beneficial effects of acid sphingomyelinase inhibition by amitryptiline in the in vivo setting of cardioplegia as employed in cardiac surgery.

\section{Acknowledgements}

This work was supported by a research grant (fortüne 1232126.2) of the Faculty of Medicine of the Eberhard-Karls University Tübingen, Germany.

\section{Author details}

'Children's University Hospital, Div. Congenital \& Pediatric Cardiac Surgery; University Hospital Tübingen, Germany. ${ }^{2}$ Dep. of Thoracic-, Cardiac- and 
Vascular Surgery; Tübingen University Hospital, Germany. ${ }^{3}$ Dep. of Internal Medicine IV, Section of Nephrology and Hypertension; Tübingen University Hospital, Germany. ${ }^{4}$ Clinic of Vascular and Thoracic Surgery,

Donaueschingen, Germany.

\section{Authors' contributions}

EU carried out the routine preoperative examinations, patient evaluation and participated in the study design and coordination. EU performed the statistical analysis. MM, FA and TW participated in the experiments and data evaluation. HA and GZ conceived of the study, and participated in its design and coordination. All authors read and approved the final manuscript.

\section{Competing interests}

The authors declare that they have no competing interests.

Received: 29 November 2010 Accepted: 28 March 2011

Published: 28 March 2011

\section{References}

1. Bai CX, Namekata I, Kurokawa J, Tanaka H, Shigenobu K, Furukawa T: Role of nitric oxide in $\mathrm{Ca} 2+$ sensitivity of the slowly activating delayed rectifier K+ current in cardiac myocytes. Circ Res 2005, 96:64-72.

2. Murriel CL, Churchill E, Inagaki K, Szweda LI, Mochly-Rosen D: Protein kinase Cdelta activation induces apoptosis in response to cardiac ischemia and reperfusion damage: a mechanism involving $B A D$ and the mitochondria. J Biol Chem 2004, 279:47985-47991.

3. Ak K, Akgun S, Tecimer T, Isbir CS, Civelek A, Tekeli A, et al: Determination of histopathologic risk factors for postoperative atrial fibrillation in cardiac surgery. Ann Thorac Surg 2005, 79:1970-1975.

4. Khoynezhad A, Jalali Z, Tortolani AJ: A synopsis of research in cardiac apoptosis and its application to congestive heart failure. Tex Heart Inst $J$ 2007, 34:352-359.

5. Zhang S, Sun Z, Liu L, Hasichaonu : Carvedilol attenuates CPB-induced apoptosis in dog heart: regulationof Fas/FasL and caspase-3 pathway. Chin Med J (Engl) 2003, 116:761-766.

6. Usta E, Mustafi M, Straub A, Ziemer G: The nonselective beta-blocker carvedilol suppresses apoptosis in human cardiac tissue: a pilot study. Heart Surg Forum 2010, 13:E218-E222.

7. Usta E, Mustafi M, Scheule AM, Ziemer G: Suppressing apoptosis with milrinone simulating extracorporeal circulation: a pilot study. Thorac Cardiovasc Surg 2010, 58:285-290.

8. Usta E, Renovanz M, Mustafi M, Ziemer G, Aebert H: Human cardiac tissue in a microperfusion chamber simulating extracorporeal circulationischemia and apoptosis studies. J Cardiothorac Surg 2010, 5:3.

9. Hannun YA: Functions of ceramide in coordinating cellular responses to stress. Science 1996, 274:1855-1859.

10. Kolesnick RN, Kronke M: Regulation of ceramide production and apoptosis. Annu Rev Physiol 1998, 60:643-665.

11. Argaud L, Prigent AF, Chalabreysse L, Loufouat J, Lagarde M, Ovize M: Ceramide in the antiapoptotic effect of ischemic preconditioning. Am J Physiol Heart Circ Physiol 2004, 286:H246-H251.

12. Zhou H, Summers SA, Birnbaum MJ, Pittman RN: Inhibition of Akt kinase by cell-permeable ceramide and its implications for ceramide-induced apoptosis. J Biol Chem 1998, 273:16568-16575.

13. Teichgraber V, Ulrich M, Endlich N, Riethmuller J, Wilker B, De OliveiraMunding CC, et al: Ceramide accumulation mediates inflammation, cell death and infection susceptibility in cystic fibrosis. Nat Med 2008, 14:382-391.

14. Brenner B, Ferlinz K, Grassme H, Weller M, Koppenhoefer U, Dichgans J, et al: Fas/CD95/Apo-l activates the acidic sphingomyelinase via caspases. Cell Death Differ 1998, 5:29-37.

15. Tewari M, Quan LT, O'Rourke K, Desnoyers S, Zeng Z, Beidler DR, et al: Yama/CPP32 beta, a mammalian homolog of CED-3, is a CrmAinhibitable protease that cleaves the death substrate poly(ADP-ribose) polymerase. Cell 1995, 81:801-809.

16. Bielawska AE, Shapiro JP, Jiang L, Melkonyan HS, Piot C, Wolfe CL, et al: Ceramide is involved in triggering of cardiomyocyte apoptosis induced by ischemia and reperfusion. Am J Pathol 1997, 151:1257-1263.

17. Gulbins E, Jekle A, Ferlinz K, Grassme H, Lang F: Physiology of apoptosis. Am J Physiol Renal Physiol 2000, 279:F605-F615.
18. Chanani NK, Cowan DB, Takeuchi K, Poutias DN, Garcia LM, del Nido PJ, et al: Differential effects of amrinone and milrinone upon myocardial inflammatory signaling. Circulation 2002, 106:1284-1289.

19. Azuma M, Yamane M, Tachibana K, Morimoto Y, Kemmotsu O: Effects of epinephrine and phosphodiesterase III inhibitors on bupivacaineinduced myocardial depression in guinea-pig papillary muscle. $\mathrm{Br} J$ Anaesth 2003, 90:66-71.

20. Fukutomi T, Satoh K, Ogoshi S, Ichihara K: Effects of pimobendan and EGIS 9377, cardiotonic agents, and OG-Vl, a nucleoside-nucleotide mixture, administered during reperfusion after ischemia on stunned myocardium in dogs. Coron Artery Dis 2000, 11:83-90.

21. Ghosh S, Ng LL, Talwar S, Squire IB, Galinanes M: Cardiotrophin-1 protects the human myocardium from ischemic injury. Comparison with the first and second window of protection by ischemic preconditioning. Cardiovasc Res 2000, 48:440-447.

22. Vanden Hoek TL, Qin Y, Wojcik K, Li CQ, Shao ZH, Anderson T, et al: Reperfusion, not simulated ischemia, initiates intrinsic apoptosis injury in chick cardiomyocytes. Am J Physiol Heart Circ Physiol 2003, 284:H141-H150.

23. Miyamoto S, Howes AL, Adams JW, Dorn GW, Brown JH: Ca2+ dysregulation induces mitochondrial depolarization and apoptosis: role of $\mathrm{Na}+/ \mathrm{Ca} 2+$ exchanger and AKT. J Biol Chem 2005, 280:38505-38512.

24. Communal C, Sumandea M, de TP, Narula J, Solaro RJ, Hajjar RJ: Functional consequences of caspase activation in cardiac myocytes. Proc Natl Acad Sci USA 2002, 99:6252-6256.

25. Ashkenazi A, Dixit VM: Death receptors: signaling and modulation. Science 1998, 281:1305-1308

26. Kubasiak LA, Hernandez OM, Bishopric NH, Webster KA: Hypoxia and acidosis activate cardiac myocyte death through the Bcl-2 family protein BNIP3. Proc Natl Acad Sci USA 2002, 99:12825-12830.

27. Danial NN, Korsmeyer SJ: Cell death: critical control points. Cell 2004 116:205-219.

28. Koval M, Pagano RE: Intracellular transport and metabolism of sphingomyelin. Biochim Biophys Acta 1991, 1082:113-125.

29. Prieschl EE, Baumruker T: Sphingolipids: second messengers, mediators and raft constituents in signaling. Immunol Today 2000, 21:555-560.

30. Chalfant CE, Rathman K, Pinkerman RL, Wood RE, Obeid LM, Ogretmen B, et al: De novo ceramide regulates the alternative splicing of caspase 9 and $\mathrm{BCl}-\mathrm{x}$ in $\mathrm{A} 549$ lung adenocarcinoma cells. Dependence on protein phosphatase-1. J Biol Chem 2002, 277:12587-12595.

31. Villa P, Kaufmann SH, Earnshaw WC: Caspases and caspase inhibitors. Trends Biochem Sci 1997, 22:388-393.

32. Duan H, Orth K, Chinnaiyan AM, Poirier GG, Froelich CJ, He WW, et al: ICELAP6, a novel member of the ICE/Ced-3 gene family, is activated by the cytotoxic T cell protease granzyme B. J Biol Chem 1996, 271:16720-16724.

33. Pieper AA, Verma A, Zhang J, Snyder SH: Poly (ADP-ribose) polymerase, nitric oxide and cell death. Trends Pharmacol Sci 1999, 20:171-181.

34. Oliver FJ, de la RG, Rolli V, Ruiz-Ruiz MC, de Murcia G, Murcia JM: Importance of poly(ADP-ribose) polymerase and its cleavage in apoptosis. Lesson from an uncleavable mutant. J Biol Chem 1998, 273:33533-33539.

35. Plas DR, Thompson CB: Cell metabolism in the regulation of programmed cell death. Trends Endocrinol Metab 2002, 13:75-78.

36. Kroemer $\mathrm{G}$ : The proto-oncogene $\mathrm{BCl}-2$ and its role in regulating apoptosis. Nat Med 1997, 3:614-620.

37. Amos GJ, Wettwer E, Metzger F, Li Q, Himmel HM, Ravens U: Differences between outward currents of human atrial and subepicardial ventricular myocytes. J Physiol 1996, 491:31-50.

38. Relling DP, Hintz KK, Ren J: Acute exposure of ceramide enhances cardiac contractile function in isolated ventricular myocytes. Br J Pharmacol 2003, 140:1163-1168.

doi:10.1186/1749-8090-6-38

Cite this article as: Usta et al:: The challenge to verify ceramide's role of apoptosis induction in human cardiomyocytes - a pilot study. Journal of Cardiothoracic Surgery 2011 6:38. 